\title{
Gender Differences in Patients with Intravenous Thrombolytic and Conservative Treatment for Acute Ischemic Stroke
}

\author{
Erasmia Broussalis $^{1 *}$, Alexander B. Kunz ${ }^{1}$, Gernot Luthringshausen ${ }^{1}$, Gunther Ladurner ${ }^{2}$, Eugen Trinka ${ }^{1}$ and Monika Killer ${ }^{1,2}$
}

${ }^{1}$ Paracelsus Medical Universitiy Christian Doppler Klinik Department of Neurology Ignaz-Harrer-Str. 79 A-5020 Salzburg, Austria

${ }^{2}$ Paracelsus Medical University, Christian Doppler Klinik, Research Institute of Neurointervention, Iganz-Harrer-Str. 79, A-5020 Salzburg, Austria

\begin{abstract}
Background: Stroke is the third leading cause of death and the main cause of long term disability in western societies.

Methods: In the 5 years 2005 to 2009, 2872 ischemic stroke patients were admitted to our stroke unit and registered in a national database. The data was analyzed retrospectively.

Results: $50.8 \%$ of the patients were women. The mean age of the patients was 69.5 [18-97]. The mean NIHS at admission was 7.2 [0 - 40], at discharge 4.9 [0 - 37]. $22.9 \%$ of all admitted stroke patients were treated with IV thrombolysis. Women treated with thrombolysis were significantly older than men (mean age 73.7, range $28-97$ vs. 68.2 ranges $18-89, p<0.001$ ). Although a highly significant improvement of NIHS was seen in both genders after thrombolytic treatment, women had trends towards less gain in thrombolysis
\end{abstract}

Conclusions: In a clinic with high turnover rates and a thrombolysis rate of $22.9 \%$ we could confirm that patients of both genders benefit from thrombolytic treatment, whereby women did not show such a significant improvement most likely due to older age compared to men.

\section{Introduction}

Stroke is the leading cause of death and disability worldwide [1-4]. A higher absolute number of women than men are affected by stroke, because stroke rates increase dramatically in the older age groups and women have a higher life-expectancy [5-7]. Post stroke functional recovery and quality of life are consistently poorer in women than in men $[8,9]$.

Thrombolysis, an intravenous application of recombinant tissue plasminogen activator (rt-PA) is now the evidence- based treatment strategy, as suggested by the National Institute of Neurological Disorders and Stroke (NINDS) rt-PA Stroke Study and the European Cooperative Acute Stroke Study (ECASS) trials [10-13].

Frequencies of patients of both genders have shown a trend toward women being less likely to receive thrombolysis treatment [7]. Preliminary analysis suggested that gender may influence response to therapy with rt-PA [14]. Women and men have differences in risk factor profiles and stroke etiology. With regard to thrombolytic treatment it is still unknown whether women benefit as well as men $[8,15]$.

Austria is a country with a universal health care system and a low level of income inequality, implying that gender treatment differences should be small [16].

In this study we aimed to compare the outcomes after thrombolysis in men and women based on the common risk factors, etiology of stroke and localization.

\section{Materials and Methods}

\section{Study population}

All patients from the Austrian Stroke Unit registry, a nation wide database, who were admitted to our stroke unit in Salzburg presenting with ischemic stroke including transient ischemic attack (TIA) from 2005 to 2009 were analyzed. For analysis of conservative versus thrombolytic treatment of ischemic stroke patients we excluded patients with TIA`s.
Our data included information on demographic characteristics, risk factors, medication history, baseline and follow-up stroke severity, measured by National Institutes of Health Scale (NIHSS), information on functional outcome at discharge and after 3 months as assessed by modified Rankin Scale (mRS). Further, patients were also registered with date and time of symptom onset, arrival time at hospital, arrival time at stroke unit, and time of first imaging. We documented the onset to needle time and door to needle time.

Etiology was classified by the Trial of Org 10172 in Acute Stroke Treatment criteria (TOAST) [17]. We documented subtype, localization and classification of stroke, subdivided into transient ischemic attack, minor stroke and stroke.

Common risk factors were documented including high blood pressure, diabetes, previous stroke and myocardial infarction, cardiovascular disease, hyperlipidaemia, atrial fibrillation, periphery artery occlusive disease (PAOD), current smoking and alcohol consumption.

Following complications were analyzed: Intracerebral hemorrhage ( $\mathrm{ICH})$, recurrent and progressive stroke, cerebral edema, hydrocephalus, epileptic seizures, cardial complications and need for decompressive surgery.

Cardioembolism, makroangiopathy, haemodynamic cause,

Corresponding author: Erasmia Broussalis, Paracelsus Medical Universitiy Christian Doppler Klinik, Department of Neurology Ignaz-Harrer-Str. 79 A-5020 Salzburg, Tel: +43-662-4483-0; Fax: +43-662-3034; E-mail: e.broussalis@salk.at

Received June 02, 2011; Accepted July 20, 2011; Published July 28, 2011

Citation: Broussalis E, Kunz AB, Luthringshausen G, Ladurner G, Trinka E, et al. (2011) Gender Differences in Patients with Intravenous Thrombolytic and Conservative Treatment for Acute Ischemic Stroke. J Neurol Neurophysiol 2:117. doi:10.4172/2155-9562.1000117

Copyright: (c) 2011 Broussalis E, et al. This is an open-access article distributed under the terms of the Creative Commons Attribution License, which permits unrestricted use, distribution, and reproduction in any medium, provided the original author and source are credited. 
Citation: Broussalis E, Kunz AB, Luthringshausen G, Ladurner G, Trinka E, et al. (2011) Gender Differences in Patients with Intravenous Thrombolytic and Conservative Treatment for Acute Ischemic Stroke. J Neurol Neurophysiol 2:117. doi:10.4172/2155-9562.1000117

coagulopathy, artery dissection and high blood pressure were defined as stroke etiology.

Clinical progress was documented by a computed tomography (CT) scan. The first CT was obligate within 24 hours or at time of clinical detoriation.

\section{Treatment}

All patients admitted to our stroke unit were monitored (blood pressure and ECG over 24 hours) and received prophylaxis of deepvein thrombosis [13].

Patients who were excluded from thrombolytic treatment obtained oral antiplatelet treatment (non-IVT).

All patients received intravenous thrombolytic treatment (IVT) based on ECASS 1-3 [13,22,23]. Patients with undefined symptom onset received thrombolytic treatment after diagnosing a mismatch in magnetic resonance tomography through diffusion and perfusion weighted sequences. The determined volumes of the regions with abnormal perfusions were compared with the volumes of the acute diffusion weighted lesions. If the final infarct size was larger than one third of the diffusion area, a mismatch was diagnosed, and a thrombolytics treatment was initiated. Patients who did not implement the ECASS criteria nor had no documented mismatch were excluded from thrombolytic treatment.

Thrombolysis was implemented, including a total rt-PA dose of 0.9 $\mathrm{mg} / \mathrm{kg}-10 \%$ given in the first minute as a bolus and the remainder as an infusion over one hour - to a maximum dose of $90 \mathrm{mg} / \mathrm{kg}$, according to the admittance criteria of the European Medicines Agency EMEA [24].

Secondary stroke prophylaxis was initiated according to the most recent guidelines [18-21].

For thrombolysis exclusion and inclusion we complied with the SITS-MOST criteria (Safe Implementation of thrombolysis in StrokeMonitoring Study) [25].

\section{Statistical analysis}

SPSS (TM), version 17.0, was used for data analysis. Data were checked for normal distribution using the 1-sample KolmogorovSmirnov test. When normality assumption was not fulfilled, variables were presented as medians (range) or frequencies (percentages), as applicable. To obtain differences in patients with and without intravenous thrombolysis and to compare gender differences, the two-tailed Mann-Whitney U-test was used. As non-parametric test for multiple independent samples the Kruskal-Wallis $\mathrm{H}$ test was used. To access multivariate correlations of quantitative variables, linear regression analysis were used on natural $\log$ transformed variables, when normality assumption was not fulfilled. A p-value of less than 0.05 was considered significant, a p-value less than 0.01 as highly significant. In case of multiple comparisons, the Bonferroni correction method was used.

To exclude an age dependency a multivariate analysis was performed. When normal distribution was not fulfilled the data was logarithmised.

\begin{tabular}{|c|c|c|c|c|c|c|}
\hline & \multicolumn{3}{|l|}{ Thrombolysis } & \multicolumn{3}{|l|}{ No Thrombolysis } \\
\hline & MEN & WOMEN & $p<$ & MEN & WOMEN & $P<$ \\
\hline Mean age & $68.18(n=154)$ & $73.66(n=155)$ & 0.001 & $67.02(n=526)$ & $74.69(n=514)$ & 0.001 \\
\hline Mean NIH score at admission & $10.62(n=149)$ & $11.50(n=153)$ & 0.163 & $6.72(n=528)$ & $9.04(n=577)$ & 0.001 \\
\hline Mean NIH score at discharge & $6.53(n=147)$ & $7.66(n=144)$ & 0.463 & $5.21(n=514)$ & $6.64(n=542)$ & 0.004 \\
\hline Patients with NIH score 0-7 at admission & $36.7 \%(54 / 147)$ & $32.2 \%(46 / 143)$ & 0414 & $68.2 \%(360 / 528)$ & $57.9 \% 334 / 577)$ & 0.001 \\
\hline Patients with NIH score 8-14 at admission & $34.7 \%(51 / 147)$ & $37.1 \%(53 / 143)$ & 0.675 & $18.4 \%(97 / 528)$ & $19.6 \%(113 / 577)$ & 0.609 \\
\hline Patients with NIH score over 15 at admission & $28.6 \%(42 / 147)$ & $30.8 \%(44 / 143)$ & 0.683 & $10.8 \%(57 / 528)$ & $20.9 \% 121 / 577)$ & 0.001 \\
\hline mRS 3 months outcome $\leq 2$ & $60.7 \%(34 / 56)$ & $60 \%(27 / 45)$ & 0.942 & $65.3 \%(209 / 320)$ & $63.4 \%(226 / 356)$ & 0.620 \\
\hline mRS 3 months outcome & 1.6 (range $0-6$ ) & 2.5 (range $0-6$ ) & & 1.83 (range0-6) & 1.86 (range $0-6$ ) & 0.702 \\
\hline Door to needle time & $51.71 \min (n=152)$ & 56.14 in $(n=145)$ & 0.082 & --- & ---- & ---- \\
\hline Time from onset to stroke unit & $153 \min$ & $154 \min$ & 0.384 & $787.38 \mathrm{~min}$ & $791.22 \mathrm{~min}$ & 0.221 \\
\hline \multicolumn{7}{|l|}{ Stroke subtype } \\
\hline Lacunar syndrome & $14.5 \%(22 / 152)$ & $9.6 \%(14 / 145)$ & 0.204 & $17.1 \%(91 / 531)$ & $11.9 \%(69 / 579)$ & 0.014 \\
\hline Total anterior circulation syndrome & $10.5 \%(16 / 152)$ & $18.6 \%(27 / 145)$ & 0.048 & $7.3 \%(39 / 531)$ & $10.9 \%(63 / 579)$ & 0.043 \\
\hline Partial anterior circulation syndrome & $68.4 \%(104 / 152)$ & $67.6 \%(98 / 145)$ & 0.878 & $45.01 \%(239 / 531)$ & $53.7 \%(311 / 579)$ & 0.005 \\
\hline Posterior circulation syndrome & $5.9 \%(9 / 152)$ & $4.1 \%(6 / 145)$ & 0.483 & $29.4 \%(156 / 531)$ & $22.8 \%(132 / 579)$ & 0.013 \\
\hline Obscure & $0.6 \%(1 / 152)$ & $0 \%(0 / 145)$ & 0.328 & $0.7 \%(4 / 531)$ & $0.7 \%(4 / 579)$ & 0.903 \\
\hline \multicolumn{7}{|l|}{ Lokalization } \\
\hline Left hemisphere & $53.9 \%(82 / 152)$ & $54.5 \%(79 / 145)$ & 0.927 & $39.9 \%(12 / 579)$ & $40.1 \%(232 / 579)$ & 0.961 \\
\hline Right hemisphere & $40.8 \%(62 / 152)$ & $40.7 \%(59 / 145)$ & 0.986 & $31.1 \%(165 / 531)$ & $36.9 \%(214 / 579)$ & 0.040 \\
\hline Both hemispheres & $0.6 \%(1 / 152)$ & $0.0 \%(0 / 145)$ & 0.329 & $0.37 \%(2 / 513)$ & $0.51 \%(3 / 579)$ & 0.726 \\
\hline Brainstem & $3.3 \%(5 / 152)$ & $4.8 \%(7 / 145)$ & 0.502 & $22.03 \%(117 / 531)$ & $17.44 \%(101 / 579)$ & 0.550 \\
\hline Cerebellum & $1.3 \%(2 / 154)$ & $0.0 \%(0 / 154)$ & 0.167 & $6.21 \%(33 / 531)$ & $5.01 \%(29 / 579)$ & 0.383 \\
\hline \multicolumn{7}{|l|}{ Etiology of stroke } \\
\hline Microangiopathy & $16.5 \%(25 / 151)$ & $20 \%(25 / 145)$ & 0.876 & $100 \%(531 / 531)$ & $100 \%(579 / 579)$ & \\
\hline Thrombembolism & $15.5 \%(30 / 193)$ & $18.2 \%(34 / 186)$ & 0.478 & $25.6 \%(136 / 531)$ & $25.6 \%(148 / 579)$ & 0.986 \\
\hline Macroangiopathy & $55.4 \%(107 / 193)$ & $59.7 \%(111 / 186)$ & 0.691 & $45.2 \%(240 / 531)$ & $54.05 \%(313 / 579)$ & 0.005 \\
\hline Haemodynamic & $40.4 \%(78 / 193)$ & $28.5 \%(22 / 186)$ & 0.020 & $42.6 \%(226 / 531)$ & 36.8 \% (213/579) & 0.130 \\
\hline Koagulopathy & $8.3 \%(16 / 193)$ & $5.9 \%(11 / 186)$ & 0.370 & $8.1 \%(43 / 513)$ & $9.7 \%(56 / 579)$ & 0.359 \\
\hline Thrombolysis treatment & $50.9 \%(193 / 379)$ & $49.1 \%(186 / 379)$ & & --- & ----- & --- \\
\hline
\end{tabular}

Table 1: Demographics and baseline characteristics of men and women treated with and without IV Thrombolysis. 
Citation: Broussalis E, Kunz AB, Luthringshausen G, Ladurner G, Trinka E, et al. (2011) Gender Differences in Patients with Intravenous Thrombolytic and Conservative Treatment for Acute Ischemic Stroke. J Neurol Neurophysiol 2:117. doi:10.4172/2155-9562.1000117

\begin{tabular}{|c|c|c|c|c|c|c|}
\hline & \multicolumn{3}{|l|}{ Thrombolysis } & \multicolumn{3}{|l|}{ No Thrombolysis } \\
\hline & MEN & WOMEN & $p<$ & MEN & WOMEN & $P<$ \\
\hline High blood pressure & $77 \%(118 / 153)$ & $71.6 \%(111 / 155)$ & 0.397 & $78.5 \%(417 / 531)$ & $77.02 \%(446 / 579)$ & 0.687 \\
\hline Previus stroke & $16.9 \%(26 / 153)$ & $13.5 \%(21 / 155)$ & 0.402 & $25.8 \%(137 / 531)$ & $28.5 \%(165 / 579)$ & 0.374 \\
\hline Myocardial infarctation & $12.4 \%(19 / 153)$ & $3.2 \%(5 / 154)$ & 0.004 & $13.2 \%(70 / 531)$ & $8.6 \%(50 / 579)$ & 0.016 \\
\hline Hypercholesterinemia & $50.9 \%(78 / 153)$ & $44.8 \%(69 / 154)$ & 0.280 & $57.8 \%(307 / 513)$ & $48.7 \%(282 / 579)$ & 0.011 \\
\hline Atrial fibrillation & $34.6 \%(53 / 153)$ & $46.7 \%(72 / 154)$ & 0.074 & $28.2 \%(150 / 531)$ & $40.4 \%(234 / 579)$ & 0.001 \\
\hline PAVK & $3.9 \%(6 / 153)$ & $3.2 \%(5 / 154)$ & 0.751 & $12.05 \%(64 / 531)$ & $8.5 \%(49 / 579)$ & 0.047 \\
\hline Current smoking & $36.6 \%(56 / 153)$ & $14.9 \%(23 / 154)$ & 0.001 & $34.6 \%(184 / 531)$ & $16.1 \%(93 / 579)$ & 0.001 \\
\hline Alcohol consumption & $18.3 \%(28 / 153)$ & $12.3 \%(19 / 154)$ & 0.204 & $19.6 \%(104 / 531)$ & $9.5 \%(55 / 579)$ & 0.001 \\
\hline Cardiovascular disease & $20.3 \%(31 / 153)$ & $18.2 \%(28 / 154)$ & 0.849 & $21.3 \%(113 / 531)$ & $18.5 \%(107 / 579)$ & 0.489 \\
\hline Diabetes mellitus & $23.5 \%(36 / 153)$ & $20 \%(31 / 155)$ & 0.454 & $27.7 \%(147 / 531)$ & $26.6 \%(154 / 579)$ & 0.587 \\
\hline
\end{tabular}

Table 2: The gender differences in risk factors

\begin{tabular}{|c|c|c|c|c|c|c|}
\hline & \multicolumn{3}{|l|}{ Thrombolysis } & \multicolumn{3}{|l|}{ No Thrombolysis } \\
\hline & MEN & WOMEN & $p<$ & MEN & WOMEN & $P<$ \\
\hline Complications & $20.8 \%(31 / 149)$ & $30.7 \%(35 / 114)$ & 0.474 & $13.7 \%(73 / 531)$ & $18.5 \%(107 / 579)$ & 0.034 \\
\hline Secondary hemorrhage & $7.9 \%(12 / 152)$ & $8.9 \%(13 / 145)$ & 0.740 & $1.7 \%(9 / 531)$ & $1.2 \%(7 / 579)$ & 0.498 \\
\hline Hydrocephalus & $0.0 \%(0 / 154)$ & $0.0 \%(0 / 149)$ & - & $0.0 \%(0 / 531)$ & $0.0 \%(0 / 579)$ & \\
\hline Re stroke & $2.5 \%(3 / 118)$ & $0 / 96$ & 0.116 & $0.6 \%(3 / 531)$ & $1.4 \%(8 / 579)$ & 0.171 \\
\hline Cerebral edema & $1.9 \%(3 / 152)$ & $4.1 \%(6 / 145)$ & 0.278 & $2.8 \%(15 / 531)$ & $2.6 \%(15 / 579)$ & 0.811 \\
\hline Seizure & $0.0 \%(0 / 152)$ & $0.0 \%(0 / 145)$ & - & $0.5 \%(3 / 531)$ & $1.4 \%(8 / 579)$ & 0.171 \\
\hline Cardiovascular decompensation & $1.3 \%(2 / 152)$ & $2.1 \%(3 / 145)$ & 0.615 & $1.9 \%(10 / 531)$ & $3.3 \%(19 / 579)$ & 0.146 \\
\hline Cardial arrhythmia & $1.3 \%(2 / 152)$ & $1.4 \%(2 / 145)$ & 0.962 & $1.3 \%(7 / 531)$ & $2.8 \%(16 / 579)$ & 0.092 \\
\hline Pulmonary embolism & $0.0 \%(0 / 152$ & $0.0 \%(0 / 145)$ & - & $0.4 \%(2 / 531)$ & $0.2 \%(1 / 579)$ & 0.514 \\
\hline Progressive stroke & $3.9 \%(6 / 152)$ & $6.2 \%(9 / 145)$ & 0.374 & $7.3 \%(39 / 531)$ & $7.6 \%(44 / 579)$ & 0.873 \\
\hline Myocardial infarction & $0.6 \%(1 / 152)$ & $1.4 \%(2 / 145)$ & 0.535 & $0.4 \%(2 / 531)$ & $0.5 \%(3 / 579)$ & 0.726 \\
\hline Decompressive surgery & $0.65 \%(1 / 154)$ & $1.3 \%(2 / 155)$ & 0.567 & $0.6 \%(5 / 530)$ & $0.3 \%(3 / 577)$ & 0.407 \\
\hline Died & $3.2 \%(5 / 154)$ & $5.8 \%(9 / 155)$ & 0.280 & $2.6 \%(14 / 531)$ & $6.04 \%(35 / 579)$ & 0.007 \\
\hline
\end{tabular}

Table 3: The gender differences of complications in patients.

\section{Results}

From 2005 to 2009, 2872 patients were registered in our data base. Patients with TIA's ( $\mathrm{n}=1523)$ were excluded from analysis. Mean age was 69.5 [18 - 97], including $50.8 \%$ women and $49.2 \%$ men, with mean NIHS at admission of 7.18 , at discharge of 4.88 . Mean mRS at discharge was 2.45 .

IV thrombolysis was administered in $22.9 \%$ (309 patients) of our patients when excluding TIA's from analysis. Three patients received IVT based on mismatch analysis.

Most common risk factors were high blood pressure (75.8 \%) followed by hypercholesterinaemia (53.1\%) and atrial fibrillation $(32.7$ $\%)$.

Our inpatient mortality was $3 \%$ ( 88 of 2872 patients); most common cause of death was cerebral edema (54.2\%) and cardiovascular diseases (18.1\%).

\section{Gender differences}

Demographics and baseline characteristics of men and women treated with and without IV thrombolysis are depicted in Table 1. We analyzed 154 men and 155 women with IV thrombolysis (IVT) and 526 men and 514 women without IVT. Women were significantly older than men $[\mathrm{p}<0.001]$ in both groups.

Women with IVT showed a trend to higher NIHSS at admission (mean NIHSS 11.50 in women compared to 10.62 in men) with no significant difference $[\mathrm{p}<0.191]$. Non-IVT patients showed a significant difference of women with a higher NIHSS at admission (mean NIHSS 9.04 in women compared to men with 6.72 [p<0.001]).
Multivariate analysis showed a significant better outcome in younger patients treated with thrombolysis compared to older patients without treatment with thrombolysis $(\mathrm{p}<0.026)$.

For better comparison, patients were divided into three NIH groups: patients with minor (NIHSS 0-7), moderate (NIHSS 8-14) and major involvement (NIHSS 15+). IVT patients were almost equally distributed in all NIHSS groups with no significant gender difference. Patients without IVT were more common in NIHSS group 0-7, with significant differences in women in $0-7$ and $15+$ NIH group $[\mathrm{p}<0.001]$.

Significant improvement in both groups was evident at discharge. IVT group showed no significant difference between genders [ $\mathrm{p}<0.463$ ], however in the non-IVT group with less favorable outcome in women. $[\mathrm{p}<0.001]$

After 3 months in IVT group mRS for men was 1.6 and 2.5 in women. In non-IVT group there was an improvement by documented mRS of 1.83 in men and 1.86 in women. In IVT group $60.7 \%$ men and $60 \%$ women had an mRS 2, defined as good clinically outcome and in non-IVT group $65.3 \%$ men and $63.4 \%$ women, respectively.

There was no significant difference in time of stroke onset to admission $[\mathrm{p}<0.384 / \mathrm{p}<0.221]$ and in door to needle time $[\mathrm{p}<0.082]$ between genders (men $51.7 \mathrm{~min}$ and women $56.1 \mathrm{~min}$ ).

Most common stroke subtype was partial anterior circulation syndrome with no gender difference in IVT group [p<0.145], but significantly towards women $[\mathrm{p}<0.005]$ in non-IVT patients.

Concerning risk factors, myocardial infarction $[p<0.004]$ and current smoking $[\mathrm{p}<0.001]$, were more frequent in men of the IVT group Table 2. In the non-IVT group, men were more affected by PAOD 
Citation: Broussalis E, Kunz AB, Luthringshausen G, Ladurner G, Trinka E, et al. (2011) Gender Differences in Patients with Intravenous Thrombolytic and Conservative Treatment for Acute Ischemic Stroke. J Neurol Neurophysiol 2:117. doi:10.4172/2155-9562.1000117

[p<0.047], myocardial infarction $[\mathrm{p}<0.016]$, hypercholesterinemia $[\mathrm{p}<0.011]$, current smoking $[\mathrm{p}<0.001]$ and alcohol consumption $[\mathrm{p}<0.001]$. Women altogether were more likely to have atrial fibrillation than men with significant difference $[\mathrm{p}<0.074$ in IVT; $\mathrm{p}<0.001$ in nonIVT].

Complication rate was higher in IVT patients but with no significant gender difference Table 3.

The mortality rate in all our patients was $3.1 \%$. In IVT patients the mortality rate was $5.8 \%$ in women compared to $3.2 \%$ in men, in non-IVT patients mortality rate was $6.0 \%$ in women and $2.6 \%$ in men. Mean NIHSS of these patients at admission was 15; mean age was 72.4 in men and 81.7 in women. Deceased IVT patients showed a remarkably longer door to needle time (men $123.20 \mathrm{~min}$, women $131.60 \mathrm{~min}[\mathrm{p}<0.903])$ compared with stroke survivors.

\section{Discussion}

Stroke affects a greater number of women than men because of their increased longevity. Stroke rates increase dramatically in older age groups [7]. It has been reported that frequency of thrombolysis is less likely in women [7]. Women were reported with less favorable outcome [26], although thrombolysis treatment was associated with improvement in clinical outcome [13].

Thrombolytic treatment rates in Europe are documented with 7.5 $\%$ [27]. In our single center retrospective study $22.9 \%$ of our stroke patients received thrombolytic treatment, with favorable outcome and mean $\mathrm{mRS}$ at discharge of 2.45 .

It is interesting that our median time from stroke onset to arrival at the stroke unit is very low with $140 \mathrm{~min}$ (2hours and 20min), according to a recent study from De Silva et al. with a median hospital arriving time from stroke onset of $1245 \mathrm{~min}$ (20hours and 45min) [28]. One reason for this remarkable difference may be a well organized emergency system in Salzburg with well trained physicians on board of the ambulances and the common use of rescue helicopters. Another reason for this result is the raising stroke knowledge in Salzburg's population.

To our knowledge, until now, no similar study with these high thrombolysis rates was published.

To ensure best treatment for stroke patients, we explored possible differences between genders.

There was no significant difference in percentage of women treated with thrombolysis compared to men. Less favorable outcome in women in regard to case fatality and functional ability 3 months after stroke is mainly a result of the higher age of women $[29,26]$. Also in our study, women were significantly older than men $[p<0.001]$ and showed worse outcome after 3 month.

It was documented that functional outcome and quality of life was poorer in women than in men [7]. We could show a tendency to higher NIHSS in women compared to men independent of treatment.

For better differentiation we compared three NIHSS groups Table 1. Patients with more severe stroke symptoms were more likely to receive thrombolysis therapy. In the non-IVT group women showed a significantly less favorable outcome, especially in the 0-7 and $15+$ NIHSS group $[p<0.001]$, which could not be demonstrated in women treated with thrombolysis, indicating the importance of rt-PA treatment.

Both genders improved significantly after thrombolysis, while women showed a non significant tendency to higher NIHSS overall. Based on the fact that stroke severity measured by NIHS score appeared to be related to poorer outcome [30].

It has been described that time of symptom onset to arrival at the stroke unit is higher in women compared to men [31,7]. We could not reveal a gender difference, as shown in other studies [30]. According to publics' awareness increasing in both genders more patients are admitted to stroke units as soon as possible.

Risk-factor assessment is important in clinical practice and in stroke research [32]. Men have more often a history of previous myocardial infarction, diabetes, current smoking and were more often heavy consumers of alcohol [33]. Our patients showed a similar history and significant gender differences $[\mathrm{p}<0.001]$.

Thromboembolism related to atrial fibrillation has been shown to be more common in women [26]. In our series significantly more women were documented with atrial fibrillation than men $[p<0.074 /$ $\mathrm{p}<0.001]$. Cardioembolic strokes are more likely to be severe than other stroke subtypes [31,34]. Higher rate of atrial fibrillation in women might therefore be an explanation for their higher NIHSS scores and worse outcomes beside higher age. These results are consistent with several publications reporting that women with stroke generally have worse outcomes than men in absence of thrombolytics [14], as well as after IV thrombolysis [6,35]. The response to IV thrombolysis might depend on the mechanism of stroke. Recanalization was seen more often in cardioembolic strokes. Women are generally more prone to cardioembolic strokes, indicating that women benefit from IV thrombolysis.

Thrombolysis-associated complications were not different in women and men [8], as revealed in our patients $[\mathrm{p}<0.474]$. ICH was more often in the IVT group than in the non-thrombolysis treatment group, but with no gender difference, as shown in the ECASS 3 study [13]. In patients without thrombolysis therapy however, the most common complication was progressive stroke.

Among deceased patients we registered more women than men, likely being a result of the higher age of women and worse NIHSS score at admission in comparison to men.

Our study has some limitations referring to the small number of patients in the 3 months follow up and that from the Austrian Stroke Unit registry the 3 months follow up was determined through $\mathrm{mRS}$ and not by the NIHS score.

\section{Summary}

Our single center retrospective study enrolled a thrombolysis rate of $22.9 \%$, in comparison to main thrombolysis rates in Europe documented with $7.5 \%$. Ou data indicates no gender difference in stroke treatment. However, as cardioembolic strokes are more likely to be severe than other stroke subtypes, and atrial fibrillation is more common in women, the higher NIHS scores and worse outcomes of women beside their higher age can be explained.

\section{References}

1. Lopez AD, Mathers CD, Ezzati M, Jamison DT, Murray CJL (2006) Global and regional burden of disease and disk factors, 2001: systematic analysis of population health data. Lancet 367: 1747-1757.

2. Mahmoud RA, Etemadi MM, Donnan GA, Mokhber N, Majdi MR, et al. (2010) Excessive Incidence of Stroke in Iran, Evidence from the Mashad Stroke Incidence Study (MSIS), a Population - based Study of Stroke in the Middle East. Stroke 41: e3-10.

3. Sarti C, Rastenyte D, Cepaitis T, Tuomilehto J (2000) Internationol trends in mortalitiy from stroke. 1968 to 1994. Stroke 31: 1588-1601.

4. Hankey GJ, Warlow CP (1999) Treatment and secondary prevention of stroke: evidence, costs and effects on individuals and populations. Lancet 354: 1457-1463. 
Citation: Broussalis E, Kunz AB, Luthringshausen G, Ladurner G, Trinka E, et al. (2011) Gender Differences in Patients with Intravenous Thrombolytic and Conservative Treatment for Acute Ischemic Stroke. J Neurol Neurophysiol 2:117. doi:10.4172/2155-9562.1000117

5. Kapral MK, Fang J, Hill MD, Silver F, Richards J, et al. (2005) Sex differences in stroke care and outcome: results from the Registry of the Canadian Stroke Network. Stroke 36: 809-814.

6. Shobha N, Sylaja PN, Kapral MK, Fang MK, Hill MD, et al. (2010) Differences in stroke outcome based on sex. Neurology 74: 767-771.

7. Reeves M, Bhatt A, Jajou P, Brown M, Lisabeth $L$ (2009) Sex Differences in the Use of Intravenous rt-PA thrombolysis treatment for Acute Ischemic Stroke. A Meta-Analysis. Stroke 40: 1743-1749.

8. Förster A, Gass A, Kern R, Wolf ME, Ottomeyer C, et al. (2009) Gender Differences in Acute ischemic stroke: Etiology, Stroke patterns and response to thrombolysis. Stroke 40: 2428-2432.

9. Seshadri S, Beiser A, Kelly Hayes M, Kase CS, Au R, et al. (2006) The lifetime risk of stroke: estimates from the Framingham Study. Stroke 37: 345-350.

10. Diener HC, Ringelstein EB, Von Kummer R, Langohr HD, Bewermeyer H, et al. (2001) Treatment of Acute Ischemic Stroke With the low-molecular-weight heparin certoparin: Results of the TOPAS trial. Stroke 32: 22-29.

11. Hacke W, Kaste M, Fieschi C, Toni D, Lesaffre E, et al. (1995) Intravenous thrombolysis with recombinant tissue plasminogen activator for acute hemispheric stroke: the European Cooperative Acute Stroke Study (ECASS). Jama 274: 1017-1025.

12. Nakahima T, Minematsu K (2009) Prospects of thrombolytic therapy for acute ischemic stroke. Brain and Nerve 61: 1003-1012.

13. Hacke W, Kaste M, Bluhmki E, Brozman M, Dávalos A, et al. (2008) Thrombolysis with Alteplase 3 to 4.5 hours after Acute ischemic stroke. The New England Journal of Medicine. 359: 1317-1329.

14. Kent DM, Price LL, Ringleb P, Hill MD, Selker HP (2005) Sex Based Differences in Response to Recombinant Tissue Plasminogen Activator in Acute Ischemic Stroke: A Pooled Analysis of Randomized Clinical Trials. Stroke 36: 62-65.

15. Hill MD, Kent DM, Hinchey J, Rowley H, Buchan AM, et al. (2006) Sex-based differences in the effect of intra-arterial treatment of stroke: analysis of the PROACT-2 study. Stroke 37: 2322-2325.

16. Arrich JA, Müllner M, Lalouschek W, Greisenegger S, Crevenna R, et al. (2008) Influence of socioeconomic status and genders on stroke treatment and diagnostics. Stroke 39: 2066-2072.

17. Adams HP, Bendixen BH, Kapelle LJ, Biller J, Love BB, et al. (1993) Classification of subtype off acute ischemic stroke: definitions for use in a multicenter clinical trial. TOAST Trial of Org 10172 in Acute Stroke Treatment. Stroke 24: 35-41.

18. Asberg S, Henriksson KM, Farahmand B, Asplund K, Norrving B, et al. (2010) Ischemic Stroke and Secondary Prevention in Clinical Practise: a Cohort Study of 14529 Patients in the Swedish Stroke Register. Stroke 41: 1338-1342.

19. Baigent C, Blackwell L, Collins R, Emberson J, Godwin J, et al. (2009) Aspirin in the primary and secondary prevention of vascular disease: collaborative meta-analysis of individual participant data from randomized trials. Lancet 373: 1849-1860.

20. (2001) PROGRESS collaborative group randomized trial of perindopril-based- blood-pressure-lowering regimen among 6105 individuals with previous stroke or transient ischaemic attack. Lancet 385: 1033-1041.

21. Amarenco $P$, Labreuche $J(2009)$ Lipid management in the prevention of stroke: review and updated meta-analysis of statins for stroke prevention. Lancet Neurology 8: 453-463.

22. Larrue V, Von Kummer R, Müller A, Bluhmki E (2001) Risk factors fo Severe Hemorrhagic Transformation in Ischemic Stroke Patients treated with recombinant tissue plasminogen activator. A secondary analysis of the European-Australasian Acute Stroke Study. Stroke 32: 438-441.

23. Ford G, Freemantle N (1999) ECASS -II: Intravenous alteplase in acute ischemic stroke. Lancet 353: 9146-9165.

24. Micieli G, Marcheselli S, Tosi PA (2009) Safety and efficacy of alteplase in the treatment of acute ischemic stroke. Vascular health risk management 5 : 397-409.

25. Stemer A, Lyden P (2010) Evolution of the Thrombolytic Treatment Window for Acute Ischemic Stroke. Current Neurology and Neuroscience reports 10: 29-33.

26. Eriksson M, Glader EL, Norrving B, Terènt A, Stegmayr B (2009) Sex Differences in Stroke Care and Outcome in the Swedish National Qualitiy Register for Stroke Care. Stroke 40: 909-914.

27. Garcì-Moncò JC, Pinedo A, Escalza I, Ferreira E, Foncea N, et al. (2007) Analysis of the reasons for exclusion from tPA therapy after early arrival in acute stroke patients. Clinical Neurology and Neurosurgery 109:50-53.

28. De Silva DA, Yassin N, Toh AJ, Lim DJ, Wong WX, et al. (2010) Timing of arrival to a tertiary hospital after acute ischaemic stroke - A follow-up survey 5 years later. Ann Acad Med Singapore 39: 513-515.

29. Yashin A, Akushevich I, Ukraintseva S, Akushevich L, Arbeev K, et al. (2010) Trends in Survival and Recovery from stroke. Evidence from the national long term care survey/medicare data. Stroke 41: 563-565

30. Wahlgren N, Ahmed N, Eriksson N, Aichner F, Bluhmki E, et al. (2008) Multivariable analysis of outcome predictors and adjustment of main outcome results to baseline data profile in randomized controlled trials: Safe Implementation of Thrombolysis in Stroke-Monitoring Study (SITS-MOST) Stroke 39: 3316-3322.

31. Lysbeth LD, Brown DL, Hughes R, Majersik JJ, Morgenstern LB (2009) Acute Stroke Symptoms: Comparing women and men. Stroke 40: 2031-2036.

32. Capell LG, Vlak MHM, Algra A, Rinkel GJE (2011) Comparison of patient and proxy responses on risk factors for stroke. Acta Neurologica Scandinavica 123 160-166.

33. Gall SL, Donnan G, Dewey HM, Macdonell R, Sturm J, et al. (2010) Sex differences in presentation, severity and management of stroke in a population based study. Neurology 74: 975-981.

34. Sanak D, Herzig R, Kral M, Bártková A, Zapletalová J, et al. (2010) Is atrial fibrillation associated with poor outcome after thrombolysis? Journal of Neurology 257: 999-1003.

35. Saposnik G, Di Legge S, Webster F, Hahinski V (2005) Predictors of majo neurologic improvement after thrombolysis in acute stroke. Neurology 65 2529-2530. 